\title{
Silver Direct Electrodeposition on Ru Thin Films
}

Hyo-Chol Koo, ${ }^{a}$ Sung Ki Cho, ${ }^{a}$ Chang Hwa Lee, ${ }^{\text {b, } *}$ Soo-Kil Kim, ${ }^{\text {c,*** }}$

Oh Joong Kwon, ${ }^{\text {d }}$ and Jae Jeong Kim ${ }^{\mathrm{a}, * *, \mathrm{z}}$

${ }^{a}$ Department of Chemical and Biological Engineering, Seoul National University, Seoul 151-744, Korea

${ }^{b}$ Materials Science and Engineering Laboratory, National Institute of Standards and Technology, Gaithersburg, Maryland 20899, USA

${ }^{c}$ Fuel Cell Research Center, Korea Institute of Science and Technology (KIST), Seoul 136-791, Korea

${ }^{d}$ Department of Mechanical Engineering, University of Incheon, Incheon 402-749, Korea

Electrodeposition of $\mathrm{Ag}$ was performed on $\mathrm{Ru}$ thin films following electrochemical reduction of native Ru oxide. Oxide reduction in a tetramethylammonium hydroxide solution was critical for the formation of continuous Ag film, and a large overpotential was important for high-density nucleation. From a kinetics viewpoint, the thermal stability of the Ag film was improved by the application of a more negative potential, which suggested that better nucleation density at the initial stage of growth induced better substrate adhesion. Suppression of growth by addition of an organic additive generated a larger and more uniformly distributed initial population of Ag particles, and as a result a smooth film was obtained. (C) 2008 The Electrochemical Society. [DOI: 10.1149/1.2890394] All rights reserved.

Manuscript submitted September 17, 2007; revised manuscript received January 25, 2008.

Available electronically March 20, 2008.

Ag, which has a lower resistivity and higher oxidation resistance than copper, is now regarded as the replacement for copper for the next generation interconnection material in integrated circuits. ${ }^{1,2}$ Furthermore, recent studies have suggested that the current copper damascene process, which consists of seed layer formation, bottom-up filling electrodeposition, and chemical mechanical polishing process, could easily be replaced by $\mathrm{Ag}^{3-5}$

$\mathrm{Ru}$ has also been focused upon as a replacement for Ta or TiN to serve as the next generation barrier material because of its lower resistivity, good wetting property with copper, ${ }^{6-10}$ and wellestablished deposition processes such as chemical vapor deposition (CVD), ${ }^{11-15}$ or atomic layer deposition (ALD) ${ }^{16-18}$ that are able to produce very conformal barrier layer deposition, even at very narrow pattern sizes. The combination of $\mathrm{Ag}$ with a $\mathrm{Ru}$ barrier will have a great advantage over present materials because Ag is a noble metal that requires better glue layers in order to provide sufficient adhesion, a need that is easily met by the metallic Ru barrier. ${ }^{19}$

Direct electrodeposition is another extensively focused-upon area of research, ${ }^{6,7,10,20-28}$ as it will eliminate the burden of needing to form a conformal seed layer in a very narrow pattern size. Generally, direct electrodeposition on high-resistance barriers such as TiN or Ta requires a prenucleation step for the formation of continuous metal film ${ }^{22,23}$ due to the high interfacial energy between the deposited metal and substrate, which can be accomplished through VolmerWeber nucleation. ${ }^{29,30}$ Proper prenucleation also requires surface pretreatment for the formation of continuous metal film on a heterogeneous substrate, especially in electroless plating, which is usually performed on different materials or even on dielectrics. The native oxide layers on TiN or Ta must be removed for electroless metal deposition, ${ }^{21}$ which is also necessary for the Ru barrier. ${ }^{10}$

Following surface pretreatment, the nucleation step is essential in the deposition on the heterogeneous substrate, which is more critical for the deposition of noble metals due to their usual threedimensional nucleation with low nucleation density on a heterogeneous substrate, ${ }^{30}$ originating from their high surface energy. Previous research of direct electrodeposition has indicated that density of nucleation active sites and nucleation rate are strongly related to the applied overpotential. ${ }^{31,32}$

Because direct electrodeposition is a heterogeneous deposition process, the adhesion of a deposited film on a substrate needs to be characterized along with its effects on the electromigration resistance, which is a vital issue in metal reliability. ${ }^{23,27,33,34}$ Agglomera-

\footnotetext{
* Electrochemical Society Student Member.

** Electrochemical Society Active Member.

z E-mail: jjkimm@snu.ac.kr
}

tion, which occurs due to surface and interface diffusion, can be one of the key parameters used to estimate the adhesion and interface energy between a metal film and substrate. ${ }^{19,35}$

In the present study we focused our attention on the direct electrodeposition of $\mathrm{Ag}$ on $\mathrm{Ru}$ by optimizing surface pretreatment and nucleation steps. The thermal stability of the deposited film was tested by agglomeration at high temperature to estimate the adhesion of the film with the substrate.

\section{Experimental}

The substrate for all experiments was Ru physical vapor deposited $(\mathrm{PVD}, 50 \mathrm{~nm}) / \mathrm{Ta}(\mathrm{PVD}, 15 \mathrm{~nm}) / \mathrm{Si}$ (PVD). For electrodeposition, a sample of the substrate was cut into a $1.5 \mathrm{~cm}$ square and loaded into the electrodeposition cell, which had a contact area of $1.0 \mathrm{~cm}^{2}$ with the electrolyte. Except for the exposed area, all other parts of the conducting components were completely sealed using a homemade Teflon holder to avoid contact with the electrolyte. A TiN $(\mathrm{CVD}, 10 \mathrm{~nm}) / \mathrm{Ti}(15 \mathrm{~nm}, \mathrm{PVD}) / \mathrm{Si}$ sample was used to compare the nucleation overpotential for the Ag electrodeposition using reported pretreatment methods. ${ }^{36} \mathrm{Pt}$ wire was used as a counter electrode, and a standard calomel electrode (SCE) was used as a reference electrode. Despite that the reaction could be interfered with by the precipitation reaction between $\mathrm{Ag}^{+}$and $\mathrm{Cl}^{-}$, the high concentration of complexing agent prevented the formation of $\mathrm{AgCl}$ precipitation. Also, the potential shift due to the diffusion of ions into the reference electrode was negligible during the experiments.

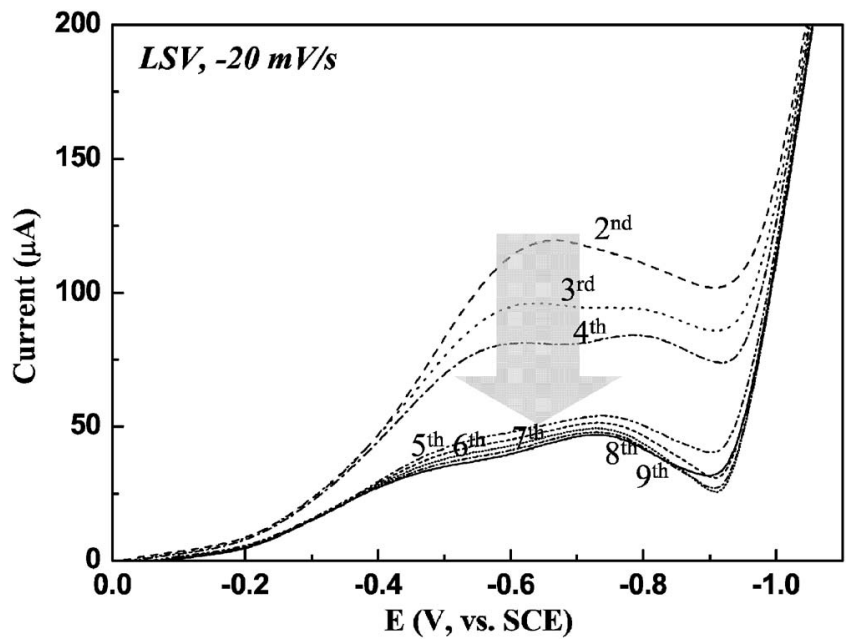

Figure 1. LSV of the Ru surface in a $0.05 \mathrm{M}$ TMAH solution. 
(a)
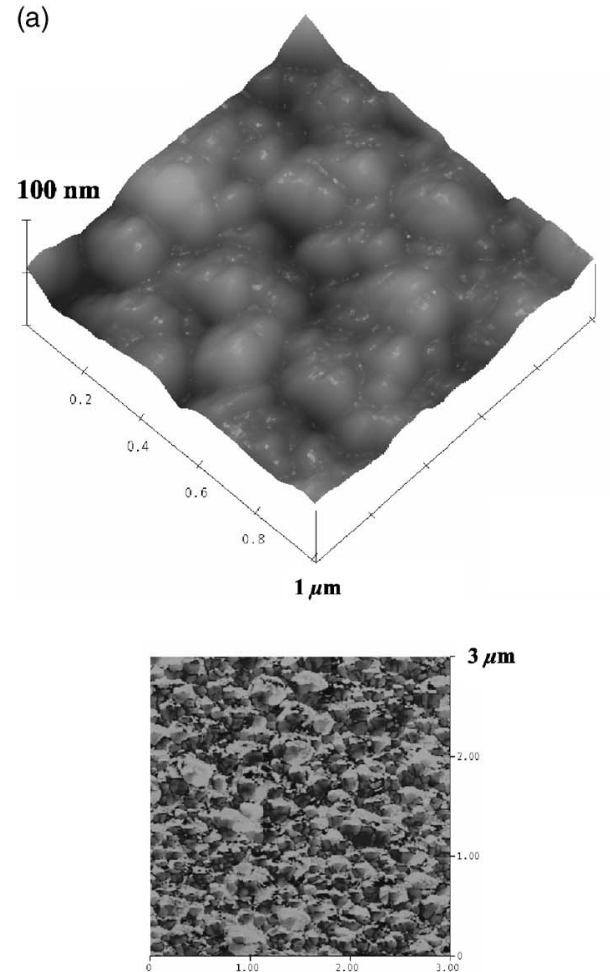

(b)
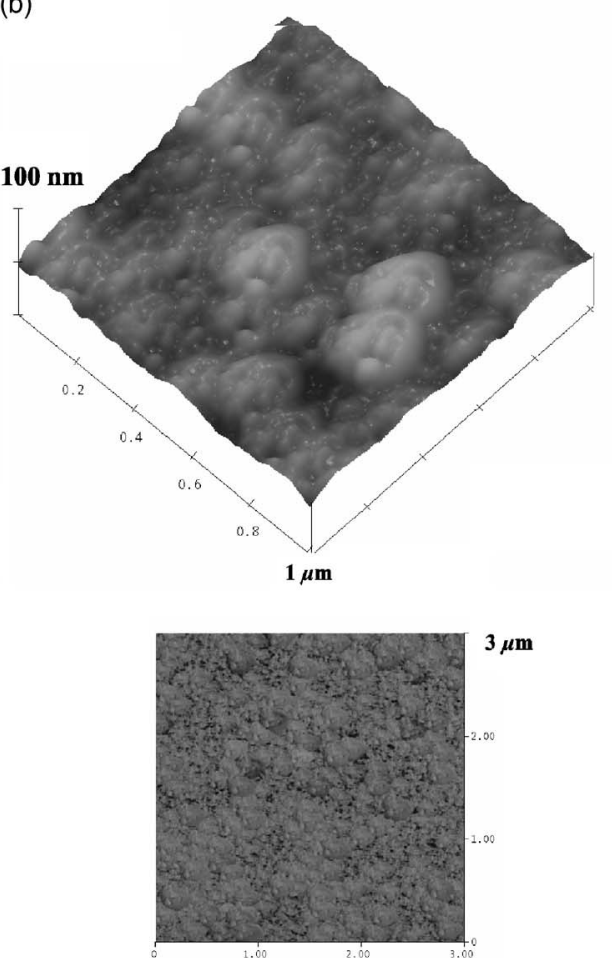

Figure 2. AFM images of (a) $\mathrm{Ru}$ (no treatment), (b) oxide-reduced $\mathrm{Ru}$, and their phase images (below).
Prior to Ag electrodeposition the native oxide of Ru was electrochemically reduced in a $0.05 \mathrm{M}$ tetramethylammonium hydroxide (TMAH) solution. After reduction, the sample was rinsed in deionized water without unloading from the cell. Next, the electrodeposition of $\mathrm{Ag}$ was performed with the electrolyte, which consisted of $\mathrm{AgNO}_{3}(0.136 \mathrm{M}), \mathrm{NH}_{4} \mathrm{OH}(0.64 \mathrm{M})$, and $\left(\mathrm{NH}_{4}\right)_{2} \mathrm{SO}_{4}(0.76 \mathrm{M})$.

The electrodeposition and electrochemical analysis was carried out with a Versastat II (EG\&G). The measurement intervals were $0.001 \mathrm{~s}$ in the case of the electrodeposition, and $1 \mathrm{~s}$ in the case of the electrochemical reduction of Ru. Film thickness and surface morphology were measured with field emission scanning electron microscopy (FESEM, Hitachi S-4800). Crystallinity was analyzed with $\mathrm{X}$-ray diffraction $(\mathrm{XRD})$.

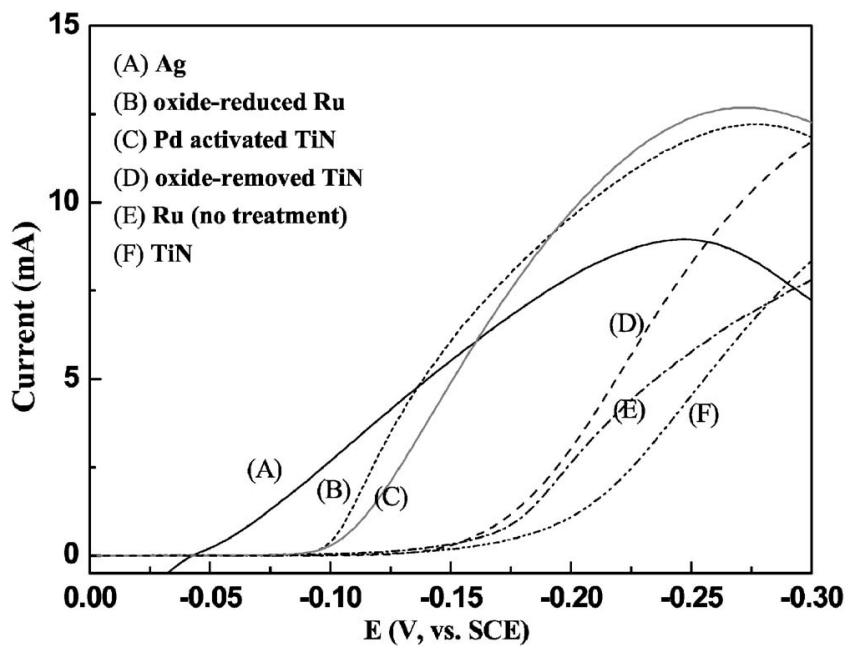

Figure 3. LSV of various substrates in a Ag electrodeposition solution: (A) $\mathrm{Ag}$, (B) oxide-reduced Ru, (C) Pd-activated TiN, (D) oxide-removed TiN, (E) Ru (no treatment), and (F) TiN.

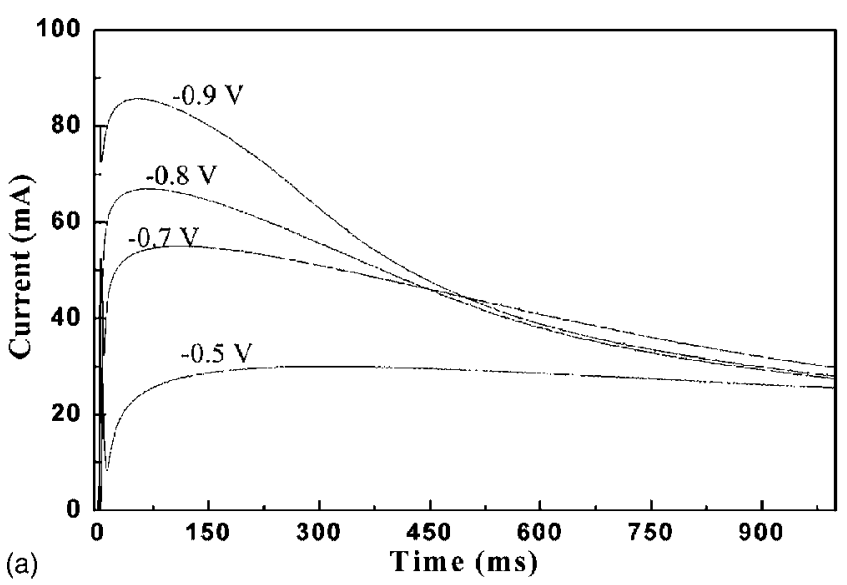

(a)

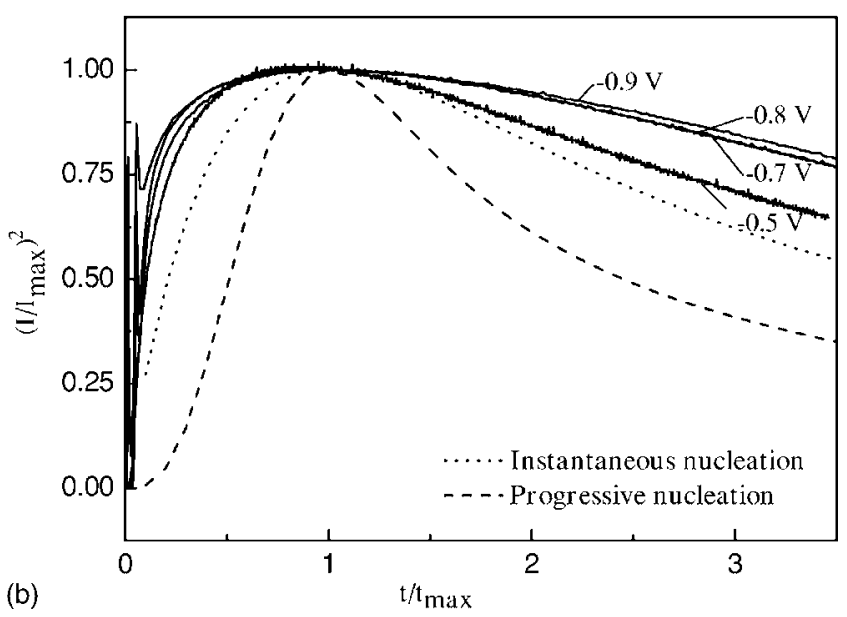

Figure 4. (a) Current density profile of the Ag deposition on oxide-reduced $\mathrm{Ru}$ with varied applied potentials, and (b) comparison with the current transition as the applied potential in the normalized current-time form varied according to the ideal Scharifker-Hills model. 


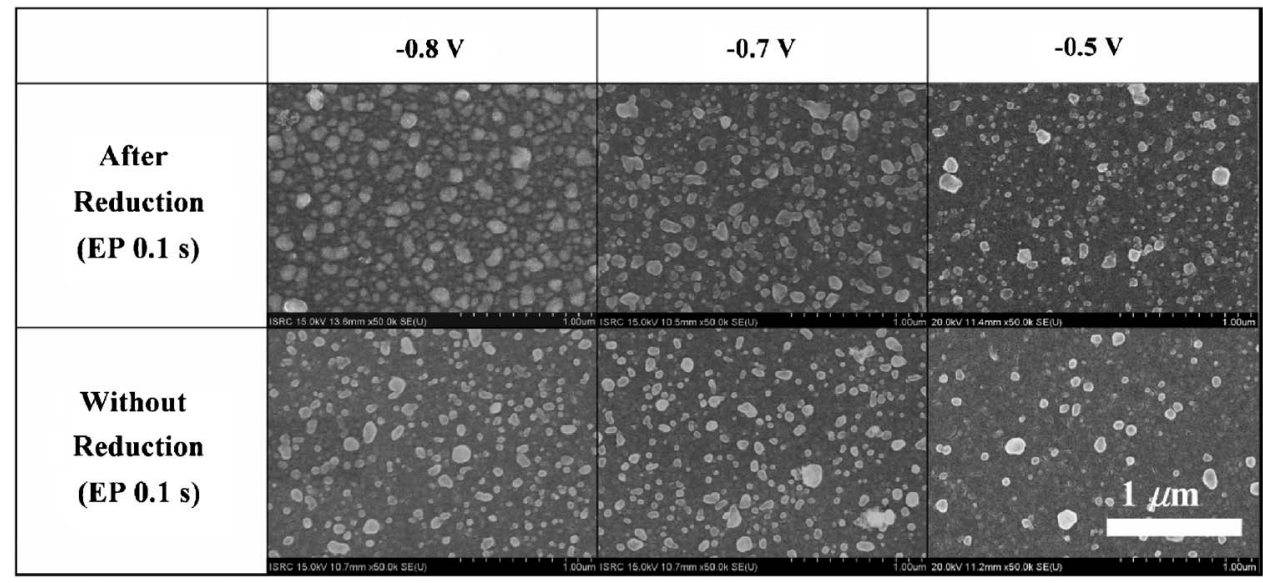

Figure 5. Nucleation profiles of the Ag electrodeposition after $0.1 \mathrm{~s}$ of deposition as the applied potential and the level of oxide reduction were varied.

The sample was annealed in a horizontal quartz tube furnace in $10 \mathrm{~mm} \mathrm{Hg}$ of nitrogen ambient at $500^{\circ} \mathrm{C}$. The temperature ramping rate was $16.7^{\circ} \mathrm{C} / \mathrm{min}$, and the sample was cooled to room temperature in nitrogen ambient.

\section{Results and Discussion}

The reduction was conducted in a strong basic solution of TMAH. As shown in the linear sweep voltammetry (LSV) of the Ru reduction (Fig. 1), a broad peak was observed during the initial sweep, and the peak intensity was continuously decreased as the sweep repeated. With respect to the surface reduction process, a negative potential of $-0.95 \mathrm{~V}$ was applied for $600 \mathrm{~s}$ to completely remove the $\mathrm{Ru}$ oxide. As a result of the reduction, the surface became hydrophilic and the surface morphology became smoother ac-
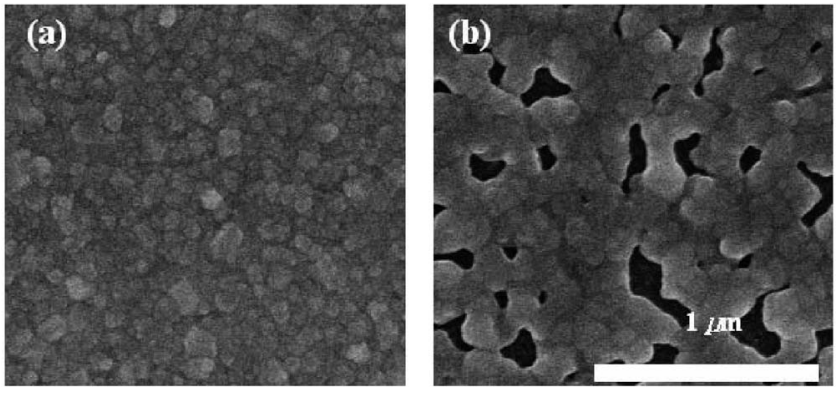

Figure 6. Surface morphology of the deposited Ag films after $1.1 \mathrm{~s}$ of deposition at $-0.8 \mathrm{~V}$ on Ru substrates, (a) with or (b) without oxide reduction. cording to atomic force microscopy (AFM) analysis, as shown in Fig. 2. Also, the phase image of AFM analysis showed more homogeneous material distribution after oxide reduction, which was a clue for the removal of $\mathrm{Ru}$ oxide. The total charge used for $\mathrm{Ru}$ reduction was calculated using the difference of the current from the first $600 \mathrm{~s}$ and subsequent $600 \mathrm{~s}$ of reduction with constant potential, and was determined as $7.7 \mathrm{mC} / \mathrm{cm}^{2}$, which was comparable with the reported value of PVD Ru reduction. ${ }^{10}$

To determine the applied overpotential for Ag direct electrodeposition, the LSV of the electrodeposition solution was also performed on several substrates to compare the nucleation overpotential. As shown in Fig. 3, compared to the curve of the Ag substrate, both Ru and $\mathrm{TiN}$ required more than a $50 \mathrm{mV}$ negative overpotential, of which the magnitude for nucleation was significantly decreased by the reduction of Ru oxide or by the formation of catalytic clusters on TiN. However, removal of Ti oxide had only a very small effect with respect to the nucleation overpotential.

Figure 4a shows the current density profiles of Ag electrodeposition on the oxide-reduced Ru substrate. As shown in the figure, the current density at the initial stage significantly increased as the applied potential decreased, which was considered as the current for nucleation. FESEM images showed that the coverage of the substrate remained low after $0.5 \mathrm{~s}$ of deposition. Despite the similar current density profiles of oxide-reduced $\mathrm{Ru}$ and TiN substrates, a continuous Ag film was not obtained on the TiN substrate even when $\mathrm{Ag}$ was deposited at a very negative potential for a long time. Normalization of the current with the Scharifker-Hills model ${ }^{37}$ (Fig. $4 \mathrm{~b})$ showed that all of the curves deviated from the ideal nucleation model. Every case, regardless of the applied potential, exhibited a larger current density than the ideal instantaneous nucleation model;

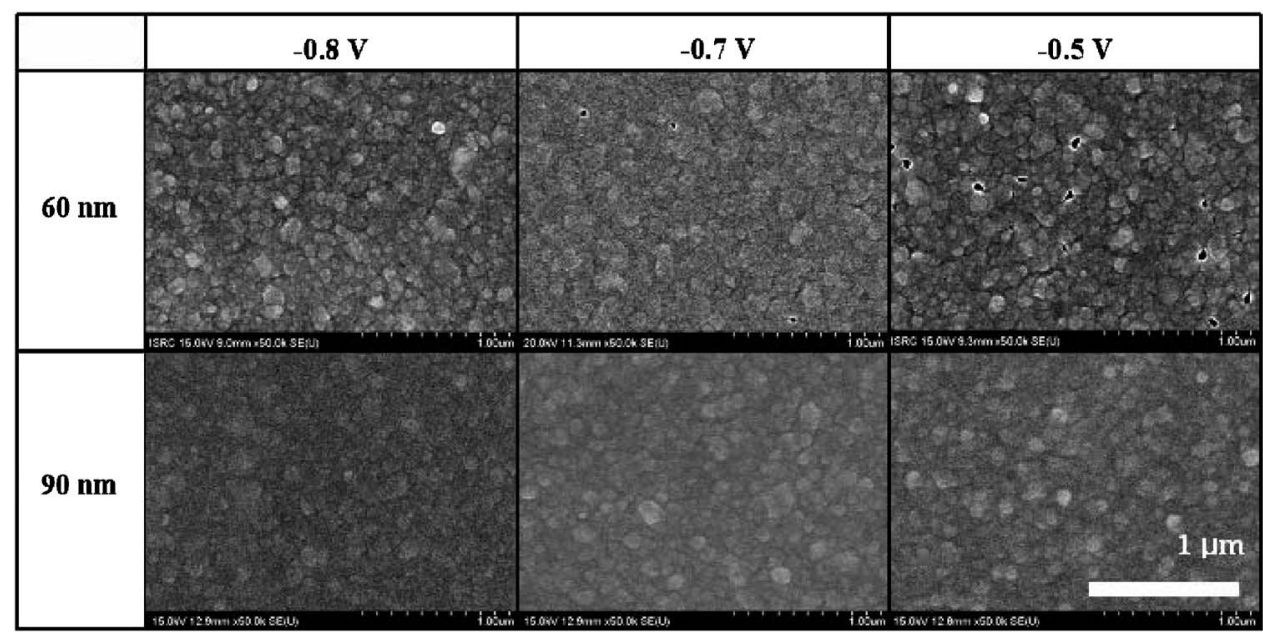

Figure 7. Surface morphology of the deposited Ag films with oxide reduction of varying thickness and applied potential. 

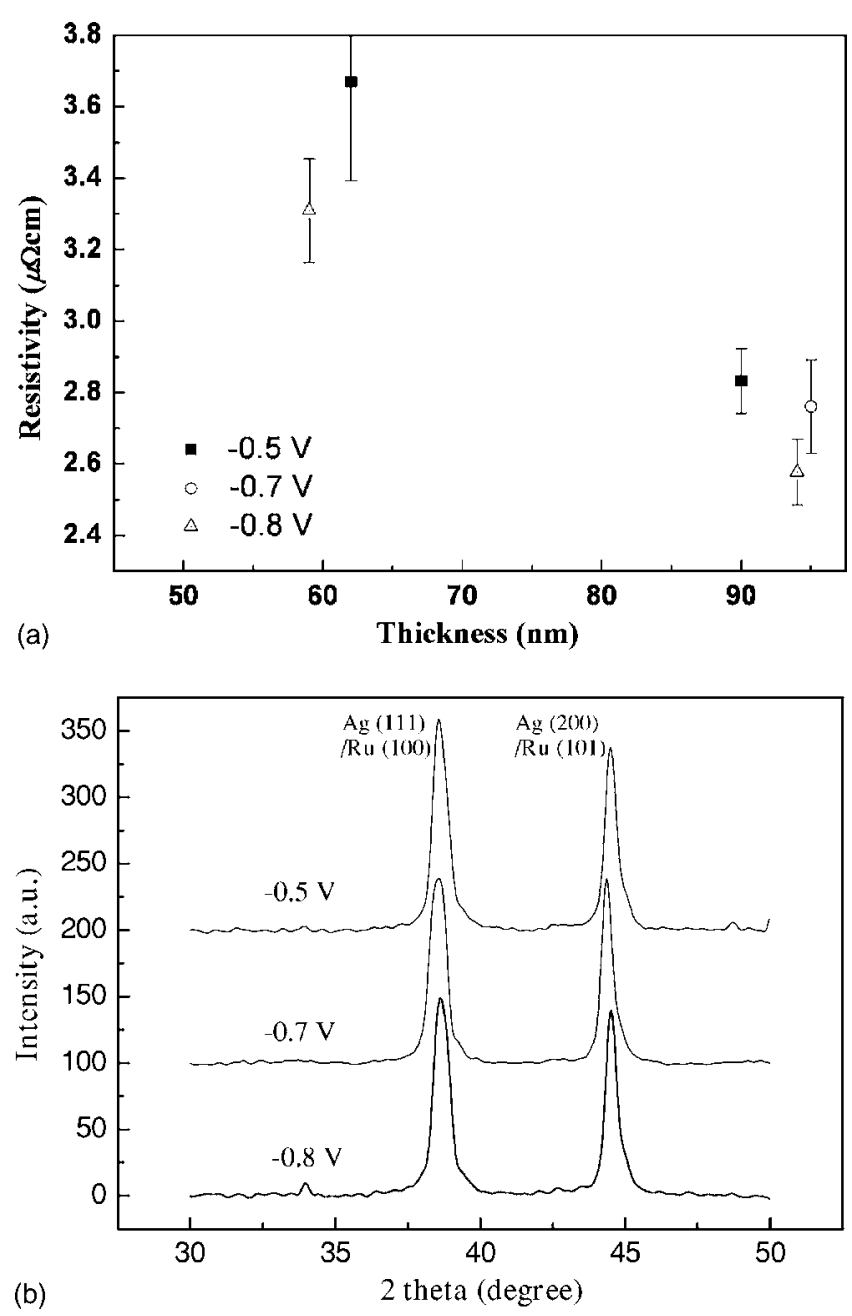

Figure 8. (a) Resistivity of the Ag films as film thickness and applied potential were varied, and (b) crystallinity of the Ag films $(60 \mathrm{~nm})$ as the applied potential was varied.

such deviation may have been due to charge-transfer governing growth or nonideal nucleation, which made deviations from the assumption of the ideal model. In this case, the early coalescence of $\mathrm{Ag}$ particles observed prior to the complete covering of the substrate as well as formation of abnormally large Ag particles might be possible reasons for the deviation. Furthermore, a strong negative potential may induce the hydrogen evolution simultaneously. However, the precise effects of these factors are not clear.
The effect of oxide reduction on the initial stage deposition with various applied potentials is shown in Fig. 5. There were obvious decreases in the nucleation density with a more positive applied potential after $0.1 \mathrm{~s}$ of deposition; however, the difference in nucleation density was not notable below $-0.8 \mathrm{~V}$ when oxide reduction was employed, whereas the increase of the nucleation density was obvious without oxide reduction. There were slight increases in current density by oxide reduction, but formation of a continuous Ag film was not possible without the oxide reduction shown in Fig. 6.

Figure 7 shows the surface morphology of various Ag films deposited on the oxide-reduced Ru substrate. Some voids were incorporated into Ag films that were deposited at more positive potentials, as in the case of the $60 \mathrm{~nm} \mathrm{Ag}$ film, which may have resulted from a low nucleation density. For $90 \mathrm{~nm}$ thick Ag films, the surface morphologies of all cases were comparable to each other, regardless of the applied potential.

The values of resistivity of the $90 \mathrm{~nm}$ films were in the range of 2.6-2.8 $\mu \Omega \mathrm{cm}$ (Fig. 8a). The $60 \mathrm{~nm} \mathrm{Ag} \mathrm{films} \mathrm{had} \mathrm{a} \mathrm{slightly} \mathrm{higher}$ resistivity and slightly larger deviation as the applied potential became more positive. As shown in Fig. 8b, there is a clear $\mathrm{Ag}(111)$ peak. Careful consideration of peak overlap between $\mathrm{Ag}$ and $\mathrm{Ru}$ must be included. The XRD data of only the Ru film revealed that the strong peak near $44^{\circ}$ is almost $\mathrm{Ru}(101)$. There was also a slight overlap between the $\operatorname{Ag}(111)$ and $\mathrm{Ru}(100)$ peaks. The grain size from the Scherrer equation was calculated to be about $25 \mathrm{~nm}$, which was smaller than the previously reported mean-free path of electrons in $\mathrm{Ag} .{ }^{4}$

Thermal stability of the $60 \mathrm{~nm}$ film was tested by annealing at $500^{\circ} \mathrm{C}$ for several hours in nitrogen ambient. As shown in Fig. 9, while the extent of agglomeration was considerably affected by the applied potential, the final state of agglomeration remained the same regardless of applied potential. The sheet resistance changes noted in Fig. 10 provided more quantitative data regarding the extent of agglomeration. Higher negative potentials reduced the accelerating rate of sheet resistance. Interestingly, with thicker films, the sheet resistance was slightly decreased, even after $4 \mathrm{~h}$ of annealing, as shown in Fig. 11. This phenomenon may be due to the different ratio between the interface and the total volume of the film. ${ }^{38}$

In this study, we found that oxide reduction of $\mathrm{Ru}$ was a critical factor for the formation of a continuous Ag film and that the applied potential affected the initial nucleation stage and the thermal stability of the film. The link between these two findings was not initially clear. As reported in previous research, the nucleation density at the initial stage is strongly affected by the applied potential, ${ }^{31,32}$ and this may be the reason for the limited kinetic stability observed during agglomeration. The film adhesion and chemical interaction between film and substrate are presumably linked to the nuclei formed at the initial stage. After the formation of nuclei, growth of $\mathrm{Ag}$ proceeds from the Ag nuclei, not the substrate, due to the large difference in nucleation overpotential. Better adhesion and dense chemical inter-

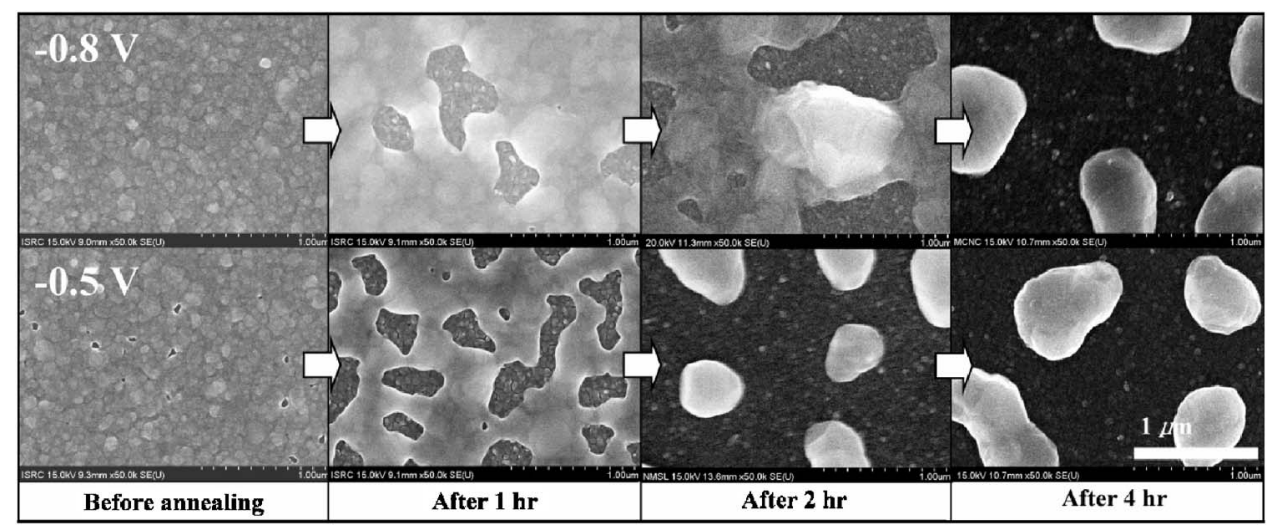

Figure 9. Surface morphology of the 60 $\mathrm{nm}$ thick $\mathrm{Ag}$ films after annealing at $500^{\circ} \mathrm{C}$ in nitrogen ambient. 


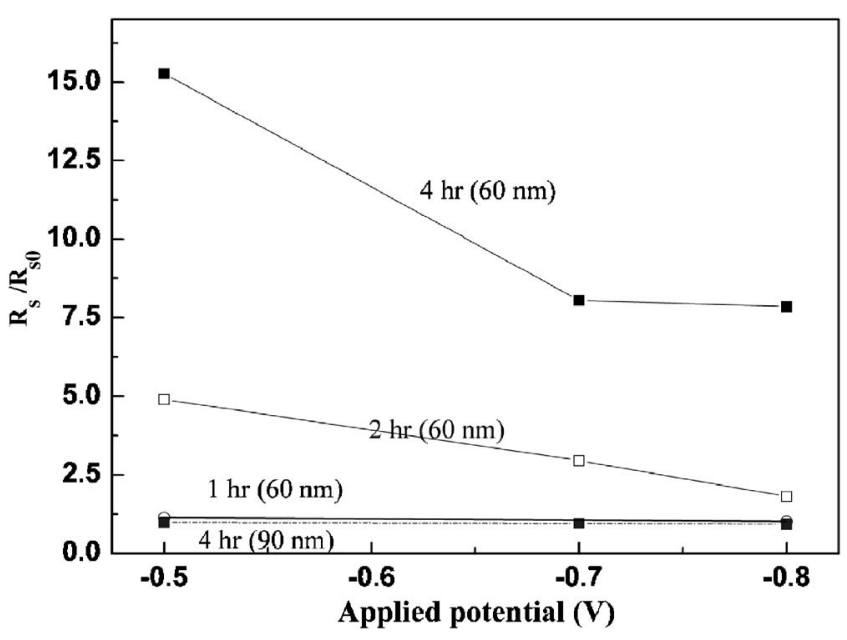

Figure 10. Sheet resistance changes of annealed Ag films as the annealing time and applied potential were varied.

action spots might be the origin of better agglomeration resistance, due to the slower interfacial diffusion of $\mathrm{Ag}$ atoms at the interface.

Addition of a suppressor was also employed to enhance nucleation. For the direct electrodeposition of $\mathrm{Cu}$ on $\mathrm{Ru}$, addition of the suppressor PEG-Cl- results in increased nucleation density. ${ }^{39}$ In this study, 3-amino-1,2,4-triazole, which has a similar structure to other $\mathrm{Cu}$ corrosion inhibitors such as benzotriazole or 5-aminotetrazole, was added to the electrolyte in order to suppress further growth. ${ }^{40}$ The addition of 3-amino-1,2,4-triazole strongly enhanced nucleation density and considerably improved the coverage of $0.1 \mathrm{~s}$ into deposition compared to cases without suppressor (Fig. 12). The LSV data in Fig. 13 showed that the addition of the suppressor slightly increased the overpotential for nucleation on both electrodes, but also decreased the difference of overpotential between electrodes, which was interpreted as a lower energy barrier for the nucleation, leading to a higher population. ${ }^{41}$ In addition, it was suggested that the preferential adsorption of suppressors on the growing Ag clusters inhibited local growth acceleration of the early stage nuclei. Therefore, when the suppressor was added to the electrolyte, a continuous growth of Ag film on the already-formed Ag cluster was suppressed
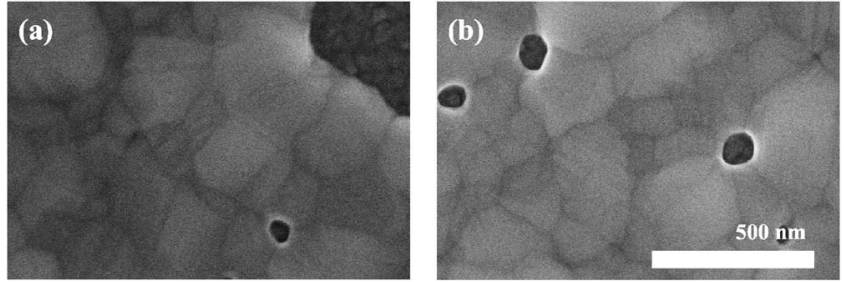

Figure 11. Surface morphology of the $\mathrm{Ag}$ film $(90 \mathrm{~nm})$ annealed at $500^{\circ} \mathrm{C}$ for $4 \mathrm{~h}$ : (a) deposited at $-0.8 \mathrm{~V}$ or (b) at $-0.5 \mathrm{~V}$.

and new cluster formation was able to begin. The higher nucleation density at the initial stage also induced better adhesion to the substrate and enhanced thermal stability.

\section{Conclusion}

Direct electrodeposition of $\mathrm{Ag}$ was performed on $\mathrm{Ru}$ thin film following electrochemical reduction of Ru oxide. At higher negative potentials the current density during the initial stage increased significantly and nucleation density was enhanced. Even though the nucleation profile was not significantly different between reduced and nonreduced $\mathrm{Ru}$ oxide, we found that the oxide reduction was a critical process for the formation of a continuous Ag thin film. The applied potential also affected the extent of agglomeration. Even though there were no significant differences in the final breakdown of the metal films, the increased rate of sheet resistance and altered surface morphology was strongly suppressed with a more negative potential. A higher nucleation density at the initial stage was closely related with better resistance to agglomeration. The nucleation density was also increased by the addition of a suppressor, which decreased the difference between the nucleation overpotential on $\mathrm{Ag}$ and $\mathrm{Ru}$.

\section{Acknowledgments}

This work was supported by KOSEF through the Research Center for Energy Conversion and Storage (RCECS), the Institute of Chemical Processing (ICP) in Seoul National University, and Dongbu HiTek.
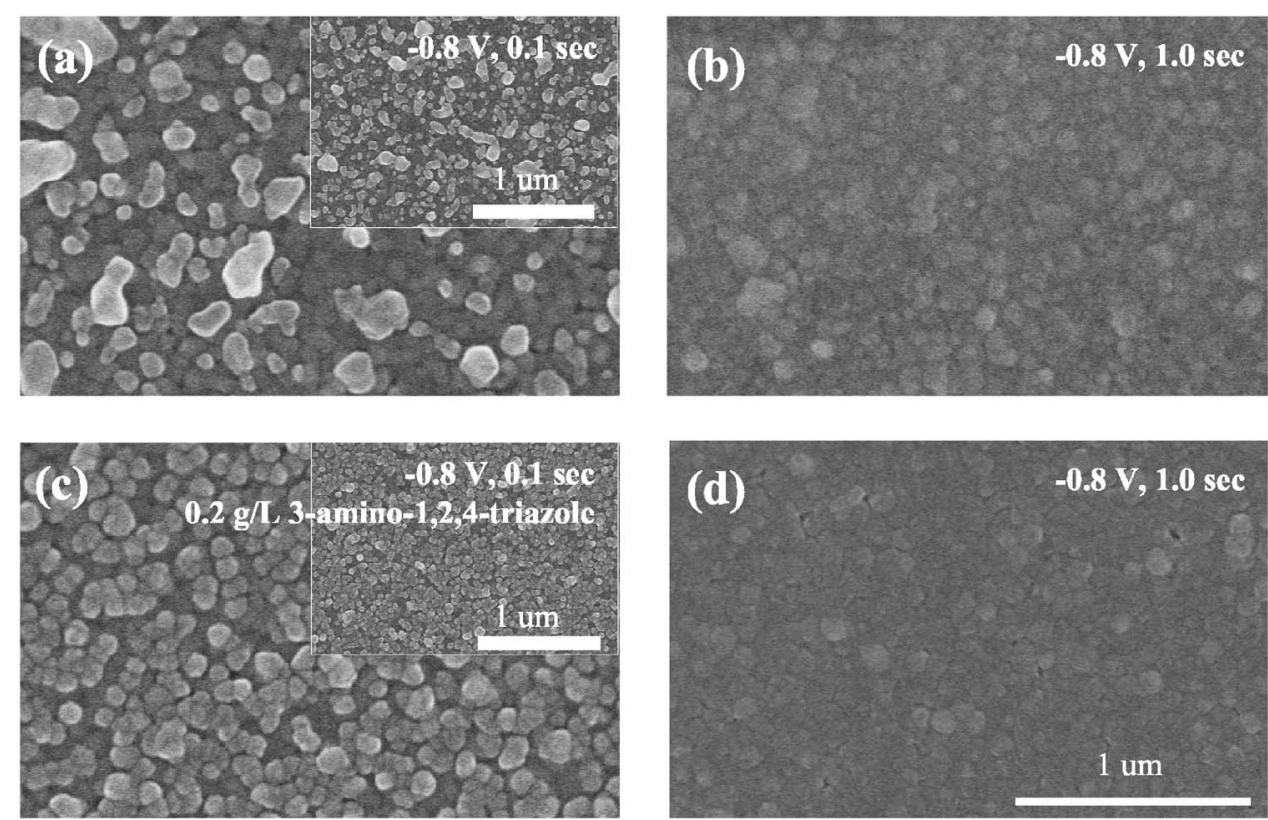

Figure 12. Surface morphology of $\mathrm{Ag}$ electroplated on oxide-reduced Ru, without suppressor (a) after $0.1 \mathrm{~s}$ of deposition, (b) after $1.0 \mathrm{~s}$ of deposition, and with $2.4 \mathrm{mM}$ of 3-amino-1,2,4-triazole, (c) after $0.1 \mathrm{~s}$, and (d) after $1.0 \mathrm{~s}$. All samples were deposited at $-0.8 \mathrm{~V}$. 

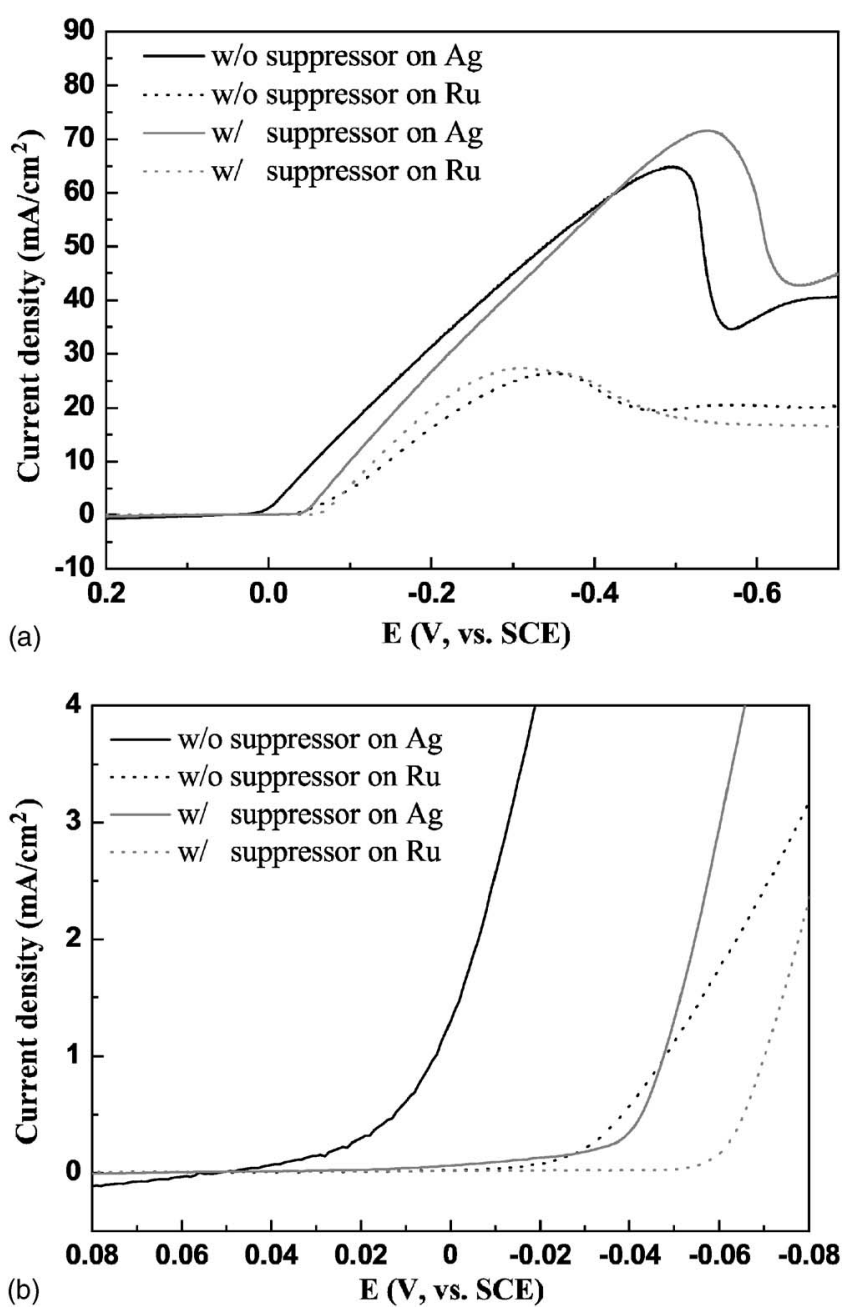

Figure 13. (a) LSV of the electroplating solution after addition of the suppressor and substrate material, and (b) a magnified section near the equilibrium potentials.

Seoul National University assisted in meeting the publication costs of this article.

\section{References}

1. T. Laursen, D. Adams, T. L. Alford, K.-N. Tu, F. Deng, R. Morton, and S. S. Lau, Thin Solid Films, 290-291, 411 (1996).

2. T. L. Alford, P. Nguyen, Y. Zeng, and J. W. Mayer, Microelectron. Eng., 55, 383 (2001).

3. B. Baker, C. Witt, D. Wheeler, D. Josell, and T. P. Moffat, Electrochem. Solid-State Lett., 6, C67 (2003).

4. D. Josell, C. Burkhard, Y. Li, Y.-W. Cheng, R. R. Keller, C. A. Witt, D. R. Kelley,
J. E. Bonevich, B. C. Baker, and T. P. Moffat, J. Appl. Phys., 96, 759 (2004).

5. E. J. Ahn and J. J. Kim, Electrochem. Solid-State Lett., 7, C118 (2004).

6. D. Josell, D. Wheeler, C. Witt, and T. P. Moffat, Electrochem. Solid-State Lett., 6, C143 (2003)

7. S. K. Cho, S.-K. Kim, H. Han, J. J. Kim, and S. M. Oh, J. Vac. Sci. Technol. B, 22 2649 (2004).

8. R. Chan, T. N. Arunagiri, Y. Zhang, O. Chyan, R. M. Wallace, M. J. Kim, and T. Q. Hurd, Electrochem. Solid-State Lett., 7, G154 (2004).

9. T. N. Arunagiri, Y. Zhang, O. Chyan, M. El-Bouanani, M. J. Kim, K. H. Chen, C T. Wu, and L. C. Chen, Appl. Phys. Lett., 86, 083104 (2005).

10. T. P. Moffat, M. Walker, P. J. Chen, J. E. Bonevich, W. E. Egelhoff, L. Richter, C. Witt, T. Aaltonen, M. Ritala, M. Leskela, and D. Josell, J. Electrochem. Soc., 153, C37 (2006).

11. S. Y. Kang, K. H. Choi, S. K. Lee, C. S. Hwang, and H. J. Kim, J. Electrochem. Soc., 147, 1161 (2000).

12. Y. Matsui, M. Hiratani, T. Nabatame, Y. Shimamoto, and S. Kimura, Electrochem Solid-State Lett., 4, C9 (2001).

13. J. J. Kim, M. S. Kim, and D. Y. Yoon, Chem. Vap. Deposition, 9, 105 (2003).

14. H. Han and J. J. Kim, J. Vac. Sci. Technol. A, 22, 1120 (2004).

15. J. Shin, D. Gay, Y.-M. Sun, J. M. White, and J. G. Ekerdt, AIP Conf. Proc., 788 , 482 (2005)

16. T. Aaltonen, A. Rahtu, M. Ritala, and M. Leskela, Electrochem. Solid-State Lett., 6, C130 (2003)

17. O.-K. Kwon, S.-H. Kwon, H.-S. Park, and S.-W. Kang, J. Electrochem. Soc., 151, C753 (2004)

18. S.-H. Kwon, O.-K. Kwon, J.-S. Min, and S.-W. Kang, J. Electrochem. Soc., 153, G578 (2006)

19. H. Kim, T. Koseki, T. Ohba, T. Ohta, Y. Kojima, H. Sato, and Y. Shimogaki, $J$. Electrochem. Soc., 152, G594 (2005).

20. C. Wang, J. Lei, S. Rudenja, N. Magtoto, and J. Kelber, Electrochem. Solid-State Lett., 5, C82 (2002)

21. M. W. Lane, C. E. Murray, F. R. McFeely, P. M. Vereecken, and R. Rosenberg, Appl. Phys. Lett., 83, 2330 (2003).

22. A. Radisic, Y. Cao, P. Taephaisitphongse, A. C. West, and P. Searson, J. Electrochem. Soc., 150, C362 (2003).

23. J. J. Kim, S.-K. Kim, and Y. S. Kim, J. Electrochem. Soc., 151, C97 (2004).

24. A. Radisic, G. Oskam, and P. Searson, J. Electrochem. Soc., 151, C369 (2004).

25. M. Zheng, M. Willey, and A. C. West, Electrochem. Solid-State Lett., 8, C151 (2005).

26. D. Josell, C. Witt, and T. P. Moffat, Electrochem. Solid-State Lett., 9, C41 (2006)

27. S. Kim and D. J. Duquette, J. Electrochem. Soc., 153, C417 (2006).

28. D. Josell, J. E. Bonevich, T. P. Moffat, T. Aaltonen, M. Ritala, and M. Leskela, Electrochem. Solid-State Lett., 9, C48 (2006).

29. L. Graham, C. Steinbruchel, and D. J. Duquette, J. Electrochem. Soc., 149, C390 (2002).

30. E. Budevski, G. Staikov, and W. J. Lorenz, Electrochemical Phase Formation and Growth, VCH, New York (1996).

31. H. Cesiulis and M. Ziomek-Moroz, J. Appl. Electrochem., 30, 1261 (2000).

32. J.-J. Lee, B. Miller, X. Shi, R. Kalish, and K. A. Wheeler, J. Electrochem. Soc., 148, C183 (2001).

33. Y. Zeng, L. Chen, Y. L. Zou, P. A. Nguyen, J. D. Hansen, and T. L. Alford, Mater Chem. Phys., 66, 77 (2000).

34. M. W. Lane, E. G. Liniger, and J. R. Lloyd, J. Appl. Phys., 93, 1417 (2003).

35. T. Hara, K. Sakata, A. Kawaguchi, and S. Kamijima, Electrochem. Solid-State Lett., 4, C81 (2001).

36. J. J. Kim and S. H. Cha, Jpn. J. Appl. Phys., Part 1, 40, 7151 (2001).

37. B. Scharifker and G. Hills, Electrochim. Acta, 28, 879 (1983).

38. R. Saxena, M. J. Frederick, G. Ramanath, W. N. Gill, and J. L. Plawsky, Phys. Rev. $B, 72,115425$ (2005)

39. M. Zheng, M. Willey, and A. C. West, Electrochem. Solid-State Lett., 8, C15 (2005).

40. J.-W. Lee, M.-C. Kang, and J. J. Kim, J. Electrochem. Soc., 152, C827 (2005).

41. T. O. Drews, A. Radisic, J. Erlebacher, R. D. Braatz, P. C. Searson, and R. C. Alkire, J. Electrochem. Soc., 153, C434 (2006). 